\title{
ASSESSING TEACHING PRESENCE IN A COMPUTER CONFERENCING CONTEXT
}

\author{
Terry Anderson \\ Professor and Canadian Research Chair in Distance Education \\ Athabasca University \\ terrya@,athabascau.ca \\ Liam Rourke \\ University of Alberta \\ Edmonton Alberta \\ lrourke@ualberta.ca \\ D. Randy Garrison \\ University of Alberta \\ Edmonton Alberta \\ Randy.Garrison@ualberta.ca \\ Walter Archer \\ University of Alberta \\ Edmonton Alberta \\ Walter.archer@ualberta.ca
}

\begin{abstract}
This paper presents a tool developed for the purpose of assessing teaching presence in online courses that make use of computer conferencing, and preliminary results from the use of this tool. The method of analysis is based on Garrison, Anderson, and Archer's [1] model of critical thinking and practical inquiry in a computer conferencing context. The concept of teaching presence is constitutively defined as having three categories - design and organization, facilitating discourse, and direct instruction. Indicators that we search for in the computer conference transcripts identify each category. Pilot testing of the instrument reveals interesting differences in the extent and type of teaching presence found in different graduate level online courses.
\end{abstract}

\section{KEYWORDS}

Teaching, CMC, instruction, formal education 


\section{INTRODUCTION}

In the one-room schools that dotted the North American landscape during the pioneer era, the tasks of a skilled and dedicated teacher were challenging, to say the least. The teacher performed several functions. Obviously, she or he provided direct instruction - in all school subjects, to children in up to nine different grades! Perhaps less obvious, the teacher had to spend long hours designing and organizing the learning experiences of the children. This teacher function often included non-traditional activities such as lighting the potbellied stove on each frigid winter morning so that the school would be habitable when the students arrived. A third teaching function that was very important in these pioneer schools was creating a community of learners by facilitating student-to-student discourse. It was obviously impossible for one teacher to provide constant direct instruction to twenty-five students in up to nine different grades. Most of the learning in the one-room school took place as children in one grade worked in a peer-learning group while the teacher was providing direct instruction to children in another grade. Frequently the teacher would assign "the big kids" - i.e., those who knew more about the subject - to help "the little kids," those who knew less about the subject. These various teaching functions are now being replicated in a new "pioneering" context, that of online learning, to which we now turn.

\section{TEACHING PRESENCE IN AN ONLINE ENVIRONMENT}

There are two reasons why we begin a paper on teaching presence in a virtual environment with a look back at teaching presence in an earlier pioneering era. First, in the earlier, supposedly simpler era of the one-room schoolhouse, it was clear that the functions of a teacher were multifacetted. In that more physical, more observable environment, it is easy to see the function of the teacher as consisting of three major roles: first, as designer of the educational experience, including planning and administering instruction as well as evaluating and certifying competence; second, as facilitator and co-creator of a social environment conducive to active and successful learning; and finally, as a subject matter expert who knows a great deal more than most learners and is thus in a position to 'scaffold' learning experiences by providing direct instruction.

Another reason for our reference to the experience of pioneer teachers in one-room schools is that it serves as an analogy to the time consuming and often frustrating experience of twenty-first century "pioneer teachers" in online learning communities. As was the case in the one-room schools in the early twentieth century, creating the necessary "warmth" in the pioneering virtual learning environments of the early twenty-first century takes considerable teacher effort. However, the imperfect tools of today are harbingers of easier and more ubiquitous online learning tools, just as the one-room schools of long ago have given place to modern, wellequipped schools in rural centers.

This paper reviews the tasks of the online teacher as gleaned from the literature and our experiences as teachers of graduate level, online courses. It then introduces a technique for systematically analyzing the context of the text-based transcripts of those courses. We expect that these tools will allow teachers to assess and then improve their own postings in online courses. We also expect that these tools can be used for research designed to test hypotheses or diagnose problems in online teaching. We conclude the paper with the preliminary results of our analysis of the transcripts from two graduate level teaching courses. 


\section{THEORETICAL FRAMEWORK}

Teaching in online courses is an extremely complex and challenging function. Therefore, study of this multifaceted function requires an appropriate theoretical perspective that frames this particular research context. This is provided by the framework of our extended research project the goal of which is to better understand teaching and learning via computer conferencing in a higher education context through the development of analytical and measurement tools that assess critical discourse in a community of inquiry [1]. Our research is based on a model of critical thinking and practical inquiry developed by Garrison, Anderson and Archer [2]. This model is framed by a community of inquiry model and used to illustrate the multifaceted components of teaching and learning in a text-based environment [1]. The three elements of this framework are: cognitive presence, social presence and teaching presence. Earlier papers have discussed methodology of transcript analysis [3], cognitive presence [4], and social presence in computer conferencing $[5,6]$. In the current paper we examine the variable that is most directly under the control of teachers--the task of creating and sustaining "teaching presence" in a text-based computer conferencing context.

In a transactional approach to education, consistent with traditional higher education values, the teacher is expected to assume certain responsibilities and fulfill an important role. Regardless of the mediated nature of the communication, "it is the teacher's responsibility to precipitate and facilitate learning that has purpose and is focused on essential concepts and worthwhile goals" [2]. Fulfilling the complex responsibilities of a teacher necessitates sustained and authentic communication between and among teachers and students. While control must be shared and choices provided, the discourse must also be guided toward higher levels of learning through reflective participation as well as by challenging assumptions and diagnosing misconceptions.

This collaborative construction of knowledge is a challenge that all educators face. However, it is made extraordinarily difficult when it is the educator's responsibility to design, facilitate, and direct learning online. For learning to occur in this lean medium of communication, dependent on written language only, a strong element of what we refer to as teaching presence is required. We will now turn to the task of defining with greater precision what teaching presence is and how it may be measured.

\section{CLASSIFICATION OF TEACHER ROLES IN COMPUTER CONFERENCING}

The initial classification of teaching presence proposed by the present authors consisted of three characteristics - design and administration, facilitating discourse, and direct instruction [1]. A review of the literature related to online teaching provides support for this classification.

Our three categories of teaching presence can be mapped directly to previous work by other researchers (see Table 1). First, it is important to note that Berge [7] categorizes four major functions of the online moderator. He adds a "technical" support role to the three we have itemized. However, while we acknowledge that providing technical assistance to students is currently an onerous function of the online teacher, like tending the prairie school stove, we believe that its importance will decrease as users become more experienced and as the tools of online learning become more intuitive and ubiquitous. Moreover, technical support can be 
provided by a variety of means (i.e. technical discussions, Frequently Asked Questions, student call centers, etc.) that do not necessarily involve the teacher [7].

Paulsen [9] and Mason [10] also divide the educational moderator's role into three major responsibilities - organizational, social, and intellectual. The one area where we depart somewhat from these authors is in terms of how we construct and define the social aspects of an educational experience. We have separated out the purely social elements as a separate element of a community of inquiry and refer to (this distinct element) it as "social presence" [5]. The creation of the social environment is the responsibility of students as well as teachers. In our model, only the social aspects of the teacher's messages that directly relate to the content contributions from the student are included in the teaching presence category. The corresponding characteristic from a teaching presence perspective is the role of facilitating discourse. Finally, we refer to the third function as "direct instruction" rather than Berge's "pedagogical" which, in its broadest sense, can refer to all three functions or to Paulsen and Mason's "intellectual" which does not necessarily denote teaching at all.

Table 1

Models of teaching roles in computer conferencing

\begin{tabular}{|c|c|c|c|}
\hline Anderson et al & Berge [6] & Paulsen [8] & Mason [9] \\
\hline $\begin{array}{l}\text { Instructional design and } \\
\text { organization }\end{array}$ & Managerial & Organizational & Organizational \\
\hline Facilitating Discourse & Social & Social & Social \\
\hline \multirow[t]{2}{*}{ Direct Instruction } & Pedagogical & Intellectual & Intellectual \\
\hline & Technical & & \\
\hline
\end{tabular}

Rossman's [11] extensive research provides empirical support for these classification systems. Through the analysis of over 3000 student end-of-course evaluations from 154 university courses, Rossman found student comments and complaints clustered into three major groupings - teacher responsibility, facilitating discussions, and course requirements. These map to our categories of direct instruction, facilitating discourse, and design and administration, respectively. Finally Coppola, Hiltz and Rotter's [12] qualitative interview research with 20 "virtual professors" identified affective, cognitive and managerial roles (changes) as major categories undergoing change through the teaching of online courses. Obviously these three match directly with our indicators of teaching presence.

Lists of hints and suggestions for conference moderators and online teachers have also been provided by many authors (see especially Salmon [8] and the many lists of hints at Berge and Collins' Moderators' Home Page). However, these provide few, if any guidelines by which teaching presence characteristics can be measured or assessed. To achieve this goal we have developed a template and tool for assessing teaching presence. We have done this through the provision of indicators and examples that clearly describe and measure the concept of teaching presence. 


\section{V.DESCRIBING TEACHING PRESENCE}

We define teaching presence as the design, facilitation, and direction of cognitive and social processes for the purpose of realizing personally meaningful and educationally worthwhile learning outcomes. Teaching presence begins before the course commences as the teacher, acting as instructional designer, plans and prepares the course of studies, and it continues during the course, as the instructor facilitates the discourse and provides direct instruction when required. Through adequate teaching presence, formal learning that facilitates personally relevant and educationally defined outcomes is achieved. We do not wish to denigrate individual learning that occurs through independent or self-directed study. However, it is only through active intervention of a teacher that a powerful communications tool such as collaborative computer conferencing [11], or cooperative learning [12] becomes a useful instructional and learning resource. Identifying and quantifying the types of teaching presence interventions give us some clues to developing better support tools for pioneers of online education.

Usually a formal distance education course consists of much more than dialogue between and among teacher and students and includes course readings, web explorations, exercises and individual and collaborative projects. Teaching presence mediates all of these components, however we have initially only used our analysis tools on the computer conferencing component of the course. We are grateful to the reviewer of this article who pointed out that the analysis of teacher presence could be extended to other components of the course and we invite subsequent researchers to follow through on this approach.

Teachers and students come to conventional higher education having already learned welldefined roles through years of common educational background and experience in the formal education system. During online learning this background and prior experience are less relevant to the context, which can invoke feelings of anomie. This forces teachers and students to explicitly define or redefine their functional roles. They must rely less on predefined roles and behavioral expectations. In addition, for the teacher "the ability to create, maintain, and control space (whatever we call it - virtual, nonplace, network) links us to notions of power and necessarily to issues of authority, dominance, submission, rebellion, and cooperation" [13]. Thus, we feel a need for systems that teachers and researchers can use to better understand the effect of their behavior in this complex environment.

We next describe each of the three categories of teaching presence, as well as indicators that are later used to measure the extent to which each category of teaching presence is represented in the transcript of a given online course.

\section{A. Design and Organization}

As in many forms of distance education, the process of designing and planning the online course is usually more extensive and time-consuming than is the analogous process in classroom based teaching. More thorough planning often results when teachers work on courses that may be visible to peers, administrators and visitors as well as their own students. Building the course in a digital format forces teachers to think through the process, structure, evaluation and interaction components of the course. Much of the learned expectation of classroom norms is not available for either student or teacher use, and thus the teacher is forced to be more explicit and transparent 
in their planning process. We refer to this component of teacher presence as design and organization.

Activities in this category of teaching presence include building curriculum materials including the creation and integration of external 'learning objects' [14] such as those available through MERLOT. 'Re-purposing' materials, such as lecture notes to provide online teacher commentaries, mini-lectures, personal insights and other customized views of course content, is another common activity that we assign to this category of teaching presence. This category also involves designing and administering an appropriate mix of group and individual activities that take place during the course. This category of teaching presence also includes the processes through which the instructor negotiates time lines for group activities and student project work, a very important aspect of online courses. Many researchers have documented the challenge to the instructor of synchronizing activities so that learners feel "in synch" with the rest of the class [6] [8].

The teacher also provides organizational service to students by providing guidelines and tips and modeling appropriate etiquette and effective use of the medium. This includes appropriate use of the reply and quote functions, and repair of communications breakdowns such as inappropriate posting or postings placed in the wrong discussion forum.

Students also need to have a sense of the "grand design" of the course and reassurance that participating in the learning activities will lead to attainment of their learning goals. We concur with Laurillard, Stratfold, Lukin, Plowman and Taylor [17] that the teacher's task is to create a narrative path through the mediated instruction and activity set such that students are aware of the explicit and implicit learning goals and activities in which they participate. Macro-level comments about course process and content are thus an important motivation and orientation component of this category of teaching presence.

Table 2

Coding scheme for Instructional Design and Organization

\begin{tabular}{ll}
\hline Indicators & Examples \\
\hline Setting curriculum & "This week we will be discussing. .." \\
Designing methods & "I am going to divide you into groups, and you will \\
debate. .." & "Please post a message by Friday. .." \\
Establishing time parameters & "Try to address issues that others have raised when \\
Utilizing medium effectively & you post" \\
& "Keep your messages short" \\
Establishing netiquette &
\end{tabular}




\section{B. Facilitating Discourse}

Facilitating discourse during the course is critical to maintaining the interest, motivation and engagement of students in active learning. We use the term discourse rather than discussion to highlight the focused and sustained deliberation that marks learning in a community of inquiry or as Scardamalia and Bereiter [19] refer to it, the " knowledge-building community."

In fulfillment of this component of teaching presence, the teacher regularly reads and comments on student postings, constantly searching for ways to support the development of the learning community. This component overlaps with many of the behaviors identified in our larger model of "social presence" [5] as the teacher is an active member of the community of inquiry. However, the teacher's role is more demanding than that of other participants, and carries with it higher levels of responsibility for establishing and maintaining the discourse that creates and sustains social presence. The teacher shares responsibility with each individual student for attainment of agreed upon learning objectives. The teacher supports and encourages participation by modeling appropriate behaviors, commenting upon and encouraging student responses, drawing in the less active participations, and curtailing the effusive comments of those who tend to dominate the virtual space.

Unlike the analogous categories used by previous researchers, our facilitating discourse category is more than the facilitation of social activities. Our facilitating discourse function differs from the "social dimension" of computer conferencing, which Henri [20] defines as "statements not related to formal content or subject matter" (p. 126). Rather, facilitation of discourse is usually integrated within direct instruction and in situ design of instructional activity. Under this heading we place teacher postings that stimulate social process with a direct goal of stimulating individual and group learning. Therefore, we tend not to search in the "coffee room" or "chat" areas of the computer conference for evidence of these indicators, but do look for indicators of support for social discourse within each message in the content focused discussions. Their presence indicates the teacher is helping to create a positive learning environment. The indicators we use to identify the facilitating discourse component of teaching presence include the identification of areas of agreement and disagreement. From a Piagetian [21] perspective, cognitive development requires that individuals encounter others who contradict their own intuitively derived ideas and notions and thereby create cognitive conflicts. It is the resolution of these conflicts that results in higher forms of reasoning. Teachers may be required to help students find congruent linkages when two seemingly contrary opinions are being expressed. Similarly, helping students articulate consensus and shared understanding, when these are already implicit in the discussion, is also useful.

Finally, the teacher's facilitation tasks include assessing the efficacy of the process. Computer conferencing has become associated with large time commitments from teachers and students [20]. Thus, we look for indicators that the teacher is "moving the discussion along" and insuring effective and efficient use of time. 
Table 3

Coding scheme for Facilitating Discourse

\begin{tabular}{ll}
\hline Indicators & Examples \\
\hline Identifying areas of agreement/disagreement & $\begin{array}{l}\text { "Joe, Mary has provided a compelling counter- } \\
\text { example to your hypothesis. Would you care to } \\
\text { respond?" }\end{array}$
\end{tabular}

Seeking to reach consensus/understanding

"I think Joe and Mary are saying essentially the same thing"

Encouraging, acknowledging, or reinforcing "Thank you for your insightful comments" student contributions

Setting climate for learning

"Don't feel self-conscious about 'thinking out loud' on the forum. This is a place to try out ideas after all."

Drawing in participants, prompting discussion "Any thoughts on this issue?" "Anyone care to comment?"

Assess the efficacy of the process

"I think we're getting a little off track here"

\section{Direct Instruction}

In this final teaching presence category, teachers provide intellectual and scholarly leadership and share their subject matter knowledge with students. Davie [23] writes that the instructor must be able to set and communicate the intellectual climate of the course or seminar, and model the qualities of a scholar. The students and the teacher have expectations of the teacher communicating content knowledge that is enhanced by the teacher's personal interest, excitement and in-depth understanding of the content. The cognitive apprenticeship model espoused by Collins \& Brown [24], Rogoff's [25] model of apprenticeship in thinking or Vygotsky's [26] scaffolding analogies illustrate an assistive role for teachers in providing instructional support to students from their position of greater content knowledge. Although many authors recommend a "guide on the side" approach to moderating student discussions, this type of laissez faire approach misinterprets a fundamental element of peer collaboration models. A key feature of such social cognition models is the adult, the expert or the more skilled peer who scaffolds a novice's learning.

The role of the teacher, in any context, involves direct instruction that makes use of the subject matter and pedagogical expertise of the teacher. Some theorists have argued that online teaching is unlike classroom based teaching in that the "the teacher must adopt the role of facilitator not content provider" [27] (p. 447). The arbitrary distinction between facilitator and content provider we find troublesome. Garrison [28] in a lively exchange focused on differentiating so called teacher-centered and student-centered instruction, makes the point that "the self-directed assumption of andragogy suggests a high degree of independence that is often inappropriate from 
a support perspective and which also ignores issues of what is worthwhile or what qualifies as an educational experience" (p. 124).

Salmon [8] writes of the diverse role of "e-moderator" which likens the teacher to a facilitator of learning. Her description suggests that the e-moderator does not require extensive subject matter expertise. She writes, "they need a qualification at least at the same level and in the same topic as the course for which they are moderating" (p. 41). We believe that such minimal subject level competency provides less than the ideal that defines high quality professional education. We recognize that economic factors and intense demand for instruction in some content areas may result in large scale educational programs being designed around "big distance education" models [1] that, through specialization and skill differential, provide adequate learning experiences for some subjects. However, we believe that there are many fields of knowledge, as well as attitudes and skills, that are best learned in forms of higher education that require the active participation of a subject matter expert in the critical discourse. This subject matter expert is expected to provide direct instruction by interjecting comments, referring students to information resources, and organizing activities that allow the students to construct the content in their own minds and personal contexts.

Table 4 illustrates the indicators we use to identify direct instruction. Presentation of content and directing questions to the group or to individual students is an important, traditional role for the teacher. Teachers also provide focus to the discussion by directing attention to particular concepts or information that is necessary to frame or pursue knowledge growth. A widely documented problem in computer conferencing is the difficulty of focusing and refining discussions so that conversation progresses beyond information sharing to knowledge construction and especially application and integration. We believe that this stalling of the discussion at the lower levels of the critical inquiry process occurs when there is not adequate teaching presence in the computer conference [27], [28], [4]. The teacher's summary is also normally not merely a neutral "weaving" of the previous postings. It often serves to develop and explicitly delineate the context in which knowledge growth has taken place.

Direct instruction also takes the form of statements that confirm understanding through assessment and explanatory feedback. Assessing student comments is time consuming and requires higher levels of knowledge than that commonly held by student participants. Often a small component of the formal course assessment relates to student participation in the conference, but in addition informal and timely teacher assessment and feedback is especially useful and valued by students.

Diagnosing misconceptions is another critical task of the on-line teacher. Often students hold misconceptions that impair their capacity to build more correct conceptions and mental schemata. The design of effective learning activities leads to opportunities for students themselves to uncover these misconceptions, but the teacher's comments and questions as direct instruction are also invaluable.

The teacher is also familiar with a wealth of resources to which they can refer students for further individual or group study. The number, quality and accessibility of these resources are increasing exponentially as more information is digitized and made available via the World Wide Web. 
Finally, the teacher may be asked to provide direct instruction on technical questions related to access to the conferencing system, manipulation of the conferencing software, operation of other tools or resources, and the technical aspects of dealing with any of the subject related tools and techniques.

Table 4

Coding scheme for Direct Instruction

\begin{tabular}{ll}
\hline Indicators & Examples \\
\hline Present content/questions & "Bates says... what do you think"
\end{tabular}

Focus the discussion on specific issues

Summarize the discussion

Confirm understanding through assessment and explanatory feedback.

Diagnose misconceptions

Inject knowledge from diverse sources, e.g., textbook, articles, internet, personal experiences (includes pointers to resources)

Responding to technical concerns
"Bates says... what do you think"

"I think that's a dead end. I would ask you to consider..."

"The original question was ...Joe said...Mary said...we concluded that...We still haven't addressed..."

"You're close, but you didn't account for... ...this is important because...

"Remember, Bates is speaking from an administrative perspective, so be careful when you say..."

"I was at a conference with Bates once, and he said...You can find the proceedings from the conference at http://www...."

"If you want to include a hyperlink in your message, you have to ..."

\section{METHOD}

The descriptions of three categories of teaching presence in the previous section provide a starting point for assessing and investigating the corresponding roles that are filled primarily by the online instructor, though often with the aid of other individuals such as instructional designers. In this section, we present a method of assembling empirical evidence in support of the existence of teaching presence and its three categories by analyzing the transcripts of computer conferences that form part of graduate level university courses.

The method utilizes a research technique called content analysis, defined as "a research methodology that uses a set of procedures to make valid inferences from text" [31]. The set of procedures includes identifying and defining a target variable, collecting samples of representative text, and devising reliable and valid rules for categorizing segments of the text. Ultimately, this process culminates in descriptive or inferential conclusions about the target variable. 
A definition of our target variable, teaching presence, and a description of its three categories has been provided above. To facilitate the classification of transcript segments into the categories, we have listed the pedagogic roles subsumed under each category and provided examples of how these roles are typically performed in conferences (see Tables 3 through 5). For example, "Acknowledging student contributions" is one of the roles of Facilitating Discourse. This role is performed in conferences with expressions such as "Thank you for your insightful comments."

The process of selecting segments of a transcript requires the researcher to stipulate what the segments or units of analysis will be. Rourke et al. [5] identified five units of analysis that have been used in computer conferencing research including proposition units, sentence units, paragraph units, thematic units, and message units. Of these five, they determined that thematic units were by far the most commonly used by researchers, although message units were the most practical.

Thematic units are identified based on their correspondence to a particular category definition [32]. The thematic unit allows coders to capture variables in their natural form; however, it is a prohibitively labor intensive process. It is also difficult to maintain what Hagelin [33] calls unit reliability, defined as "the consistency in identifying what is to be classified, i.e., the amount of information to be included in each unit." Using the message as the unit of analysis, coders generally assign an entire message to one category. The use of message units is less timeconsuming and facilitates unit reliability; however, this unit has been characterized as alternately too large or too small to adequately characterize a single item of data (for further discussion see Rourke, et al., [5]). In previous work, our research group has used both the thematic unit and the message unit [5] [6].

In the present study, we again used the message unit. However, rather than simply assigning each message unit that demonstrated some sort of teaching presence to one and only one of the categories of teaching presence, we allowed for the possibility that a single message might exhibit characteristics of more than one category. Therefore, each message posted by the instructor was coded as exhibiting or not exhibiting one or more indicator of each of the three categories of teaching presence.

This procedure proved to have a number of advantages for our investigation. First, the number of coding decisions was pre-determined for the coders - three decisions per message. This was useful for alerting coders to the need to make a decision and provided a denominator for calculating reliability. Second, the system was quickly implemented and did not require coders to determine the number or the exact text length of indicators present per unit of analysis. Third, totals for each category are easily determined and meaningfully expressed by reporting the percentage of total teacher postings that contains each of the categories.

We feel that procedure is reliable, efficient, and practical. Ultimately, the validity of this system will be judged according to two criteria: Does the procedure facilitate the objective quantification of the insights that an observer would gain from an informal reading of the transcripts? And does the procedure reveal additional insights that are not apparent from an informal reading? These questions will be addressed in the discussion section. 


\section{RESULTS}

In order to establish the reliability of the coding procedure, two raters were assigned to code all messages in both of the 13-week conference transcripts. As a result of using the message as the unit of analysis, unit reliability was $100 \%$. Interrater reliability, defined as "agreement among coders about the categorization of content," [32] was determined using Cohen's kappa. Cohen's kappa is a chance-corrected measure of interrater reliability that assumes two raters, $n$ cases, and $m$ mutually exclusive and exhaustive nominal categories [33]. The formula for calculating kappa is:

$$
\mathrm{k}=\left(\mathrm{F}_{\mathrm{o}}-\mathrm{F}_{\mathrm{c}}\right) /\left(\mathrm{N}-\mathrm{F}_{\mathrm{c}}\right)
$$

Where:

$$
\begin{aligned}
& \mathrm{N}=\text { the total number of judgments made by each coder } \\
& \mathrm{F}_{\mathrm{o}}=\text { the number of judgments on which the coders agree } \\
& \mathrm{F}_{\mathrm{c}}=\text { the number of judgments for which agreement is expected by chance. }
\end{aligned}
$$

Interrater reliability for the distance education transcript was $\mathrm{k}=.77$; for the Health Promotions transcript, interrater reliability was $\mathrm{k}=.84$. Riffe et al. [34] report "research usually reports reliability figures in the .80 to .90 range. Research that is breaking new ground with concepts that are rich in analytical value may go forward with reliability levels that are somewhat below that range."

Table 5 shows the frequency and percentage of teaching presence categories that were observed in the messages posted by the instructors of two graduate level, distance education courses. Percentages were calculated by dividing the total number of postings showing a given category of teaching presence by the total number of messages posted by that instructor. Direct instruction was the predominant category, with between $77 \%$ and $88 \%$ of all teacher messages including some form of direct instruction. Instructional design was the least frequently observed category of

\begin{tabular}{|c|c|c|c|c|}
\hline & \multicolumn{2}{|c|}{ Health Course } & \multicolumn{2}{|c|}{ Education Course } \\
\hline & $\mathrm{f}$ & $\%$ & $\mathrm{f}$ & $\%$ \\
\hline Instructional Design & 31 & 22.3 & 12 & 37.5 \\
\hline $\begin{array}{l}\text { Facilitating } \\
\text { Discourse }\end{array}$ & 60 & 43.2 & 24 & 75.0 \\
\hline Direct Instruction & 107 & 77.0 & 28 & 87.5 \\
\hline
\end{tabular}
teaching presence, with between $22 \%$ and $38 \%$ of messages addressing instructional design.

Table 5

Frequencies of teaching presence categories by instructor

Table 6 illustrates the frequency and percentage of instructor messages that addressed $0,1,2$, or 3 of the categories of teaching presence. $64 \%$ of the Health Promotions instructor's messages included only one category of teaching presence. For the Distance Education instructor, the largest percentage of messages included two categories of teaching presence. 
Table 6

Frequency and percentage of messages that included $0,1,2$, or 3 categories of teaching presence

\begin{tabular}{lcccc}
\hline & \multicolumn{2}{l}{$\begin{array}{l}\text { Graduate } \\
\text { Health Course }\end{array}$} & $\begin{array}{l}\text { Graduate } \\
\text { Course }^{\mathrm{b}}\end{array}$ & Education \\
\cline { 2 - 4 } & $\mathrm{f}$ & $\%$ & $\mathrm{f}$ & $\%$ \\
\hline & 1 & 0.7 & 0 & 0.0 \\
1 categories & 89 & 64.0 & 7 & 21.9 \\
2 category & 42 & 30.2 & 15 & 46.9 \\
3 categories & 7 & 5.0 & 10 & 31.3 \\
\hline
\end{tabular}

Note: $\quad{ }^{a} \mathrm{n}$ of instructor messages $=139$.

${ }^{\mathrm{b}} \mathrm{n}$ of instructor messages $=32$.

\section{DISCUSSION}

Our results show the pattern of teaching presence varying considerably between these two courses facilitated by two experienced online teachers. The education teacher made use of student moderators during the later weeks of the course, and thus the number of teacher postings were considerably reduced compared to the health teacher who responded to almost every student posting. In the education course, the student moderators were performing a substantial part of the teaching presence role. We have observed this phenomenon in a number of online courses. This supports our decision to refer to this element of the community of inquiry as "teaching presence" rather than "teacher presence," as a number of individuals who are not teachers often collaborate in carrying out this role. Again with regard to the two courses we examined, it should be noted that the education instructor made far fewer postings, but those postings covered, on average, a considerably higher number of the categories of teaching presence, as compared to the more frequent postings of the health sciences instructor.

Among teachers of online courses, generally, there are probably many individual variables that affect the number and content of the instructors' postings and hence their contribution to teaching presence in the conference. These will include teaching style, discipline related conceptions of the education process, size of the class, and the teachers' and students' familiarity and expertise with the medium. We report above only the aggregate totals of each of our three categories of teaching presence. It may be useful to use frequencies of individual indicators in further studies that focus on one of the three major functions of the $\mathrm{CMC}$ teacher that we have identified. The tool may also be used as a diagnostic instrument for teachers to analyze and compare the magnitude and pattern of their "teaching presence" with that of other teachers. Finally, we can see applications in which hypothesis testing is done related to any number of determinants of 
teaching presence, including work load, subject matter expertise, nature of the learning activities, and the teacher's previous experience in conventional or technology enhanced instruction.

Activities in, particularly, the instructional design category of teaching presence start well before the actual course starts, but unlike 'canned forms' of distance education, online teaching allows the instructor to revise and augment content and learning activities as the course progresses. As much of the work of this phase precedes the establishment of computer conferencing based interactions, many of the roles of this category are not visible to the students or researchers in the computer conference transcript. Thus, the record we examine is only a subset of this activity. Further, some of the teacher presence activities do not take place in common forums and are conducted through private email, voicemail or telephone. Thus, the conferencing transcript provides a snapshot and an indicator of teacher presence activities. These organizational functions vary considerably based on the features and services of the 'system' within which the formal courses are offered.

The usefulness of this tool relates to its simplicity and its diagnosis capacity. Coding using our format is relatively easy and training procedures necessary to achieve reasonably reliable results are not as time consuming as other schemes we have used. More importantly we see practicing teachers as well as researchers being able to review their postings and look for or note the absence of each of the three indicators of teaching presence. Thus, the system can be used to diagnose teaching difficulties, to help teachers reduce workloads by increasing the quality and reducing the quantity of their messages, and to increase the semantic density and functionality of their postings. The tool may also be used to analyze and describe differences in style between different types of teachers, teachers of different disciplines or to assess the contribution of student moderators or others assigned to perform ancillary teaching functions.

\section{CONCLUSION}

Marshall McLuhan is famous for his insight that "the medium is the message," implying that the impact of the medium is integral to and in some cases determinant of the message. Certainly teaching in an online environment is influenced by the absence of the non-verbal communication that occurs in the face-to-face settings of conventional education, and the reduction in the amount of paralinguistic information transmitted, as compared to some other modes of distance education such as video or audio teleconferencing. However, McLuhan also noted that each new medium takes a preceding medium for its content, and that the process of interpreting a new medium in terms of an older one (horseless carriage effect) filters our conception of the newer medium.

This process of viewing the new medium through the conceptual filter developed for the older medium necessarily colors our understanding of the teaching process in a computer mediated communications (CMC) context. Part of the challenge, as mentioned above, is to develop compensatory behaviors for the relative lack of non-verbal and paralinguistic communication in a text-based medium such as computer conferencing. Another part of the challenge is to overcome the difficulty of conceiving the role of the teacher in online courses within the long established conceptual framework that we have built in the context of conventional, face-to-face teaching. Feenberg [36] suggests that this is problematic because teachers have difficulty transposing leadership skills developed in the rich medium to the leaner medium of the text-based conference. We are not convinced that the function of teaching changes, though certainly its manifestation looks quite different in this mediated context. Especially in these "pioneering days" of online 
learning the thoughtful design of learning activities is critical to the attainment of educational outcomes. In the process of designing and using these tools, teachers are forced to be learners themselves and like all who experience learning, the learners themselves are changed. As Kiesler [37] notes, "skill changes, though triggered by the adoption of a technology, less reflect the technology itself than they are outcomes of setting up and putting in technology, and of the structure of the workplace and groups into which the technology is deployed" (p. 162).

The focus of our paper has been on developing the conceptual framework to understand, measure and improve the important function of "teaching presence" within a computer conference environment. We invite others to use and refine the concept and the tools piloted in our study, in order to better provide theoretical and empirical information to help the many pioneer online teachers of this decade.

\section{REFERENCES}

1. Garrison, D. R., Anderson, T., \& Archer, W. Critical inquiry in a text-based environment: Computer conferencing in higher education. The Internet and Higher Education, 2(2-3), 1-19, 2000

2. Garrison, D. R., \& Archer, W. A transactional perspective on teaching and learning: A framework for adult and higher education. Oxford, UK: Pergamon, 2000.

3. Rourke, L., Anderson, T., Garrison, D. R., \& Archer, W. Methodological issues in the content analysis of computer conference transcripts. International Journal of Artificial Intelligence in Education, 11(3) to appear, 2000.

4. Garrison, D.R., Anderson, T., \& Archer, W. Critical thinking, cognitive presence, and computer conferencing in distance education. American Journal of Distance Education, 15(1), 7-23, 2001.

5. Rourke, L., Anderson, T., Garrison, D. R., Archer, W. Assessing social presence in asynchronous, text-based computer conferencing. Journal of Distance Education, 14(3), 5170, 1999.

6. Rourke, L. \& Anderson, T. (in press). Exploring social communication in computer conferencing. Journal of Interactive Learning Research.

7. Berge, Z. L. Facilitating computer conferencing: Recommendations from the field. Educational Technology, 15(1) pp: 22-30, 1995. Available [Online]: http://www.emoderators.com/moderators/teach online.html

8. Salmon, G. E-moderating: The key to teaching and learning online. London: Kogan Page, 2000.

9. Paulsen, M. P. Moderating educational computer conferences. In Berge, Z. L. \& Collins, M. P. (Eds.). Computer-mediated communication and the on-line classroom in distance education. Cresskill, NJ: Hampton Press, 1995.

10. Mason, R. Moderating educational computer conferencing. DEOSNEWS Vol. 1 (19) Available [Online]: http://pchfstud1.hsh.no/hfag/litteratur/jenssen/deosnews/mason.htm, 1991.

11. Paulsen, M. P. Moderating educational computer conferences. In Berge, Z. L. \& Collins, M. P. (Eds.). Computer-mediated communication and the on-line classroom in distance education. Cresskill, NJ: Hampton Press, 1995.

12. Rossman, M. Successful online teaching using an asynchronous learner discussion Forum. Journal of Asynchronous Learning Networks, 3(2). Available [Online]: http://www.aln.org/alnweb/journal/Vol3 issue2/Rossman.htm, 1999. 
13. Coppola N., Hiltz, S.R. \& Rotter, N. Becoming a virtual professor: Pedagogical roles and ALN. Proceedings of the $34^{\text {th }}$ Hawaii International Conference on Systems Sciences, IEEE Computer Society Press, Los Alamitos, CA, (Maui, January 3-6). http://www.hicss.hawaii.edu/HICSS 34/PDFs/CLALN01.pdf, 2001

14. Harasim, L. On-line education: A new domain. In R. Mason and A. Kaye (Eds.), Mindweave: Communication, computers and distance education (pp. 91-109). Oxford: Pergamon Press, 1989.

15. Johnson, D., \& Johnson, R. Cooperation and the use of technology. In D. Jonassen (Ed.), Handbook of research for educational communications and technology (pp. 1017-1044). New York: Simon and Schuster, 1996.

16. Jones, S. Information, Internet and community: Notes towards an understanding of community in the Information Age. In. S. Jones, (Ed.) Cybersociety 2.0 (pp. 1-34) Thousand Oaks: Sage.

17. Downes, S. Learning Objects. Available [online] http://www.atl.ualberta.ca/downes/naweb/column000523.htm, 2000.

18. Laurillard, D., Stratfold, M., Luckin, R., Plowman, L. \& Taylor, J. Affordances for learning in a non-linear narrative medium. Journal of Interactive Media in Education, Available [Online]: http://www.jime.open.ac.uk/00/2, 2000.

19. Lipman, M. Thinking in education. Cambridge: Cambridge University Press, 1991.

20. Scardamalia, M., \& Bereiter, C. Computer support for knowledge-building communities. Journal of the Learning Sciences, 3(3), 265-283, 1994.

21. Henri, F. Computer conferencing and content analysis. In A. R. Kaye (Ed.), Collaborative learning through computer conferencing: The Najaden papers (pp. 115-136). New York: Springer, 1992.

22. Piaget, J. Judgment and reasoning in the child. New York: Harcourt Brace, 1928.

23. Montgomerie, T.C., Harapnuik, D. Observations on web-based course development and delivery. International Journal of Educational Telecommunications 3(2/3), 181-203, 1997.

24. Davie, L. Facilitation techniques for the on-line tutor, In R. Mason and A. Kaye (Eds.), Mindweave: Communication, computers and distance education (pp. 74-85). Oxford: Pergamon Press, 1989.

25. Collins A. \& Brown J. S. Cognitive apprenticeship: Making things visible. American Educator 15(3) 38-46, 1991.

26. Rogoff, B. Apprenticeship in thinking. New York: Cambridge University Press, 1995.

27. Vygotsky L. Mind in Society. Cambridge: Harvard University Press, 1985.

28. Mason, R. and Romiszowski, A. J. Computer-mediated communication. In D. H. Jonassen (Ed.), The handbook of research for educational communications and technology (pp. 438456). New York: Simon \& Schuster Macmillan, 1996.

29. Garrison, D. R. Andragogy, learner-centeredness, and the educational transaction at a distance. Journal of Distance Education, 3(2), 123-127, 1988.

30. Bullen, M. Participation and critical thinking in online university distance education. Journal of Distance Education, 13(2), 1-32, 1998.

31. Kanuka, H. \& Anderson, T. Online social interchange, discourse, and knowledge construction. Journal of Distance Education, 13(1), 57-74, 1998.

32. Weber, R. P. Basic content analysis, second edition. Newbury Park, CA: Sage Publications, 1990.

33. Krippendorf, K. Content analysis: An introduction to its methodology. London: Sage, 1980.

34. Hagelin, E. Coding data from child health records: The relationship between interrater agreement and interpretive burden. Journal of Pediatric Nursing 14(5) 313-321, 1999.

35. Riffe, D., Lacy, S., \& Fico, F. Analyzing media messages: Quantitative content analysis. New Jersey: Lawrence Erlbaum Associates, Inc, pp. 104, 131, 1998. 
36. Capozzoli, M., McSweeney, L. \& Sinha, D. Beyond kappa: A review of interrater agreement measures. The Canadian Journal of Statistics, 27(1), 3-23, 1999.

37. Feenberg, A. The written word. On the theory and practice of computer conferencing, In A. Kaye and R. Mason (Eds.) Mindweave: Communication, computers, and distance education (pp. 22-39). Toronto: Pergamon Press, 1986.

38. Kiesler, S. Talking, teaching and learning in network groups: Lessons from research. In A. Kaye (Ed.) Collaborative learning through computer conferencing. Berlin: Springer-Verlag, 1992.

\section{Acknowledgments}

The authors wish to acknowledge the support of the Social Science Research Council of the Government of Canada for support of this investigation.

\section{AUTHORS' BIOGRAPHIES}

Terry Anderson is a Professor and Co-director of Academic Technologies for Learning in the Faculty of Extension, University of Alberta. Terry has been a presenter at numerous conferences and has been widely published in the area of technologies for learning and distance education. terry.anderson@ualberta.ca

Liam Rourke is a doctoral student specializing in instructional technology in the University of Alberta's Department of Educational Psychology. lrourke@ualberta.ca.

D. Randy Garrison is a Professor and Dean of the Faculty of Extension at the University of Alberta. His areas of research relate to the teaching and learning transaction in the context of adult, distance, and higher education. He has published extensively in both of these areas. randy.garrison@ualberta.ca.

Walter Archer is a Professor and Associate Dean, Research, in the Faculty of Extension at the University of Alberta. He is also Acting Director of the new distance-delivered Master of Arts in Communications and Technology. He has 12 years experience with CMC and other modes of distance delivery. walter.archer@ualberta.ca. 